\title{
Deep-Breathing Biofeedback Trainability in a Virtual-Reality Action Game: A Single-Case Study with Police Trainers
}

\author{
Abele Michela ${ }^{1 *}$, Jacobien M. van Peer ${ }^{1}{ }^{\dagger}$, Jan C. Brammer ${ }^{1}{ }^{\dagger}$, Anique Nies ${ }^{1}$, Marieke M. J. W. \\ van Rooij ${ }^{2}$, Robert Oostenveld ${ }^{3,4}$, Wendy Dorrestijn ${ }^{6}$, Annika S. Smit ${ }^{5,8}$, Karin Roelofs ${ }^{1,3}$, Floris \\ Klumpers ${ }^{1,3,+2}$ and Isabela Granic ${ }^{1,7,+2}$ \\ ${ }^{1}$ Behavioural Science Institute, Radboud University, Nijmegen, Netherlands \\ ${ }^{2}$ Faculty of Behavioural, Management and Social Sciences, University of Twente, Twente, \\ Netherlands \\ ${ }^{3}$ Donders Institute for Brain, Cognition and Behaviour, Radboud University, Nijmegen \\ ${ }^{4}$ NatMEG, Department of Clinical Neuroscience, Karolinska Institutet, Stockholm, Sweden \\ ${ }^{5}$ Police Academy of the Netherlands, Apeldoorn, Netherlands \\ ${ }^{6}$ Faculty of Law, Radboud University, Nijmegen, Netherlands \\ ${ }^{7}$ Faculty of Social Sciences, McMaster University, Hamilton, Canada \\ ${ }^{8}$ University of Humanistic Studies, Utrecht, Netherlands.

\section{* Correspondence:} \\ Abele Michela \\ abele.michela@gmail.com \\ These authors have contributed equally to this work \\ ${ }^{22}$ These authors have contributed equally to this work and share last authorship \\ Word count: 9033 \\ Figures count: 5 \\ Tables count: 2
}

Keywords: Police education, police training, Virtual-Reality, stress management, autonomic arousal, heart rate variability, biofeedback.

\begin{abstract}
It is widely recognized that police performance may be hindered by psychophysiological state changes during acute stress. To address the need for awareness and control of these physiological changes, police academies in many countries have implemented Heart-Rate Variability (HRV) biofeedback training. Despite these trainings now being widely delivered in classroom setups, they typically lack the arousing action context needed for successful transfer to the operational field, where officers must apply learned skills, particularly when stress levels rise. The study presented here aimed to address this gap by training physiological control skills in an arousing action context. We developed a VirtualReality (VR) breathing-based biofeedback training in which police officers perform deep and slow diaphragmatic breathing in an engaging game-like action context. This VR game consisted of a selective shoot/don't shoot game designed to assess response inhibition, an impaired capacity in high arousal situations. Biofeedback was provided based on adherence to a slow breathing pace: the slower and deeper the breathing, the less constrained peripheral vision became, facilitating accurate responses to the in-game demands. A total of nine male police trainers completed 10 sessions over a 4-week
\end{abstract}


period as part of a single-case experimental $A B A B$ study-design (i.e., alternating sessions with and without biofeedback). Results showed that eight out of nine participants showed improved breathing control in action, with a positive effect on breathing-induced low frequency HRV, while also improving their in-game behavioral performance. Critically, the breathing-based skill learning transferred to subsequent sessions in which biofeedback was not presented. Importantly, all participants remained highly engaged throughout the training. Altogether, our study showed that our VR environment can be used to train breathing regulation in an arousing action context.

\section{Introduction}

The work of a police officer can be seen as an evolutionary paradox: in places and situations where most people would fall prey to survival instincts of self-preservation, police officers ought to act calm, with proportionality and benevolence. As a result, working as a police officer can elicit considerable stress, with high prevalence of work-related physical injuries (West et al., 2017) and stress-related symptoms (Leppma et al., 2017). Additionally, police officers are under constant scrutiny from both internal and external sources, including the public display of mistakes to ensure accountability (Skolnick \& McCoy, 1984). The nature of their dangerous work as well as being under ongoing surveillance puts a great deal of pressure on police officers.

A large body of literature has shown that, besides affecting physical and mental wellbeing (Stetz et al., 2007), stress can impair decision-making aspects which are crucial to the policing job. Experimental studies have consistently shown that under high levels of arousal, decision-making becomes more impulsive and less goal-directed (Porcelli \& Delgado, 2017), which is related to impaired control by prefrontal brain regions under stress (Arnsten, 2015; Maier et al., 2015). The detrimental effects of arousal have also been demonstrated in police, where high arousal has been associated with impaired shooting accuracy, as well as decreased inhibitory control (Hashemi et al., 2019; Nieuwenhuys et al., 2015). It is essential that police officers manage their stress while on the job to avoid costly mistakes such as the inappropriate use of force.

To train coping under stress in police officers, recent studies investigated the training of behavioral skills under pressure, which improved basic perceptuomotor skills such as shooting accuracy under threat (Nieuwenhuys \& Oudejans, 2011) or spatial orientation (Driskell et al., 2001). However, this type of training may not always improve relevant higher-level decision-making under stress, such as when asked to make shoot/don't shoot decisions (Nieuwenhuys et al., 2015). To counter the stress-induced performance drop and improve decision-making under threat, training efforts have moved beyond the focus on performance, by adding in police education elements to help officers directly manipulate the bodily stress response itself (Andersen \& Gustafsberg, 2016; Bouchard et al., 2012; Mccraty \& Atkinson, 2012). This type of biofeedback training mainly focuses on promoting emotional regulation by helping the officer control their physiological arousal through biofeedback to improve physiological awareness and gain more voluntary control over their physiology (Weerdmeester et al., 2020).

After studies showed the usefulness of biofeedback to enhance stress regulation (Bouchard, Guitard, et al., 2012; McCraty et al., 2009) several police forces worldwide have implemented training programs in which a biofeedback training component is included. However, according to a recent survey in the Netherlands, this type of training was generally negatively appraised by police officers and did not result in substantial improvements in reported stress regulation (van der Meulen et al., 2018). These disappointing results might be attributable to the fact that in current practice, biofeedback is often delivered in a passive classroom setup, which may not feel relevant to police officers and 
thereby affect their engagement. Yet, engagement is a key prerequisite for behavioral change (Holzinger et al., 2006). To promote both engagement and generalization to real-life stressful situations (skill-transfer), it is important to train stress regulation within an active and more representative action context (Seifert et al., 2018; Staller \& Körner, 2019). Yet, just as the current biofeedback applications often lack elements to make the learning process engaging and relatable, excessive stress might often prevent learning (Di Nota \& Huhta, 2019). To better reappraise stress into challenge and to improve performance under stress (Jamieson et al., 2010), it seems necessary to design a training context in which stress is kept at a moderate, optimal level that is not too low, but also not overwhelming and excessive.

One way to address previous shortcomings in classroom-based training is by creating engaging environments in Virtual-Reality (VR) where physiological control must be exerted while performing decision-making actions in an arousing context. VR is a useful tool to create controlled - yet representative - environments, allowing to elicit high levels of arousal and engagement (Miller et al., 2019; Parsons, 2015).. However, re-creating a highly realistic virtual police environment in VR can also have negative consequences on subjects' experiences due to slight mismatches with reality (Wilson \& Soranzo, 2015) and the challenges in recreating genuine verbal and tactile interactions (Michela et al., 2019). To remedy this, the use of game mechanics inspired by commercial videogames offers the possibility to re-create a genuine feeling of threat and immersion, moderate enough for learning to take place while at the same time boosting engagement (Allcoat et al., 2015; Cummings \& Bailenson, 2016; Lin, 2017; Schoneveld et al., 2019; Slater, 2018). Game mechanics also present another advantage over realistic environments in VR, which is the ease of emotional elicitation and repeatability of the experience (Lobel et al., 2016; Michela et al., 2019; Scholten \& Granic, 2019). Evidence-based trainings are however currently scarcely available (Di Nota \& Huhta, 2019) and not available at all, to the best of our knowledge, if we look for training that makes use the aforementioned VR and gaming assets. Therefore, we developed a VR environment that offers the player the possibility to train breathing-based biofeedback skills while immersed in an engaging action game (Brammer et al., 2021).

For the physiological training component, our VR application aligns with previous training practices in Dutch Police. Specifically, biofeedback training applied to police officers has mainly focused on abdominal deep breathing (van der Meulen et al., 2018), which has been shown to increase heart-rate variability (HRV) by respiratory sinus arrythmia (RSA; Hirsch \& Bishop, 1981) reflecting parasympathetic nervous system dominance (Russo et al., 2017). The influence of deep breathing on the parasympathetic nervous system can be measured in both the low frequency and high frequency spectrum of HRV (Kromenacker et al., 2018; Shaffer \& Ginsberg, 2017), as well as the coherence between breathing and HRV (Schwerdtfeger et al., 2020; Shaffer et al., 2014). This type of biofeedback has proven useful in a variety of training applications, from performance training for athletes (Jiménez Morgan \& Molina Mora, 2017) to stress and anxiety management (Goessl et al., 2017). Importantly for police applications, an elevated HRV is also related to better performance under threat (Hansen et al., 2009), and was shown to be effectively modulated by biofeedback, hence reducing stress in contexts related to police realities (Andersen et al., 2018; Bouchard et al., 2012) and also improving cognitive control (Laborde et al., 2021). In our VR environment, biofeedback was provided by modulating the width of the field of view according to breathing rate and depth, thus making physiological regulation key to being able to perform well in the game.

For the behavioral assessment components during the training in our VR environment, we focused on one of the key decision-making processes that is affected by stress and related to policerelevant go/nogo decisions, namely shoot/don't shoot decisions (Gladwin et al., 2016; Nieuwenhuys et 
al., 2015). Impairments in response inhibition are known to be especially high when individuals are primed to believe that they will need to take action and the stakes are high (Johnson et al., 2018; Taylor, 2019). Thus, we designed our game mechanic around these processes of response inhibition under stress and the impact of priming. Having those metrics imbedded in the same environment as the physiological training allows for direct measurement of the impact that physiological training has on performance.

The first overarching goal of the current study was design validation. First, we tested if the VR environment was, as hypothesized, successful in creating a challenging environment that elicits clear increases in levels of arousal (assessed via heart rate) and engagement. Second, we tested if our biofeedback a) increases slow and deep breathing and HRV, and b) raises physiological awareness for the participants. Third we explored whether our setup allowed extraction of meaningful behavioral metrics concerning response inhibition and priming. Behavioral measurements were all extracted from the VR environment, with the secondary aim of documenting interactions between behavioral metrices and physiology.

The second main goal of the current study was to perform a preliminary evaluation of the game's potential to train breathing-based biofeedback in an active action context. We hypothesized that biofeedback-driven physiological regulation skills should transfer to the same action context, when experienced without biofeedback. This preliminary proof-of-concept was performed by means of a withdrawal single-case experimental design (SCED), applied to a sample of nine trainers from the Dutch police, who took part in a ten-session training program. Withdrawal SCED has already been successfully used in investigating the potential of biofeedback (e.g., Bossenbroek et al., 2020). This design has the advantage of providing rich datasets to investigate the dynamical evolution of skill acquisition within and across sessions (Smith \& Little, 2018), and inform future research about the often overlooked aspect of minimal training length required for efficient training (Di Nota et al., 2021).

\section{Methods}

\subsection{Participants}

Participants were nine male police trainers with an average age of 43.2 years $(S D=6.45)$ and with an average of 18.4 years $(S D=8.6)$ of operational background as a police officer. Their average trait anxiety was 27 (range 23 to 34 on a scale of 20 to 80), which indicates participants in our sample to be non-anxious. Only three participants reported playing video games in their free time, to a maximum of 4 hours a day during weekends. Participants were recruited from a Police skill training center, in the Netherlands, hereafter referred to as IBT center ('Integraal Beroepsvaardigheids Training centrum'). Given that this was a proof-of-concept study, the number of participants was based on earlier studies using similar SCED methodologies (Bossenbroek et al., 2020; Ebbinghaus, 2005; Smith, 2012; Smith $\&$ Little, 2018). Participation was voluntary and handled by the coordinator at the IBT center. According to the rules of the Dutch Police, financial compensation of the police officers functioning as participants was not allowed. Therefore, for each participant a donation of 50 euros was allocated to a fund for the training of "PTSD dogs" (Actie ZeeHond, n.d.). The research procedures were approved by the ethical committee of the Faculty of Social Sciences of Radboud University Nijmegen (ECSW-2020-112). All participants provided informed consent in writing prior to participating in the study, in line with the guidelines of the Declaration of Helsinki (WMA, 2018).

This is a provisional file, not the final typeset article 


\section{$172 \quad$ 2.2.1 Physiological recordings}

173 Participants' breathing rate was measured using a respiratory inductance plethysmography (RIP) belt 174 from Plux S.A. and a BITalino (r)evolution board (Batista et al., 2017). The heart rate of the participant 175 was recorded by a Polar H10 chest strap, which extracts $\mathrm{R}-\mathrm{R}$ intervals (i.e., the time between 176 consecutive R-waves of the QRS electro cardiac signal). Both physiological recording units 177 broadcasted their data to a Raspberry Pi 4 Model B, which was also used to calculate the biofeedback 178 scores with custom-made python software, based on the open source EEGsynth library (Brammer et 179 al., 2021; Oostenveld, n.d.).

\subsubsection{VR material, model, and task}

An HTC Vive setup was used to immerse the participants in a virtual environment that consisted of a poorly lit underground parking garage. The VR trackers were set 3 to 4 meters apart, giving the player a minimal play area of 4 square meters. One of the two VR controllers was wrapped by a 3D printed case, giving the controller the weight and shape of a gun. The second VR controller was attached to the vest of the participant and used as a dispatch-radio in the game.

\subsubsection{Operationalization}

187 The VR environment was designed to incorporate game mechanics based on existing experimental laboratory tasks, as shown in Table 1. The paradigms listed were incorporated as they represent specific behavioral aspects known to be affected by stress and relevant in the decision-making processes. The first paradigm is emotional regulation, in our case physiologically influenced through breathing-based biofeedback presentation. Its implementation as a modulation of the width of the field of vision makes the biofeedback relevant for the player, since in action contexts it is easy to ignore the biofeedback if it does not interfere with action. Modulating the peripheral view directly impacts the difficulty of detecting approaching enemies in the VR environment.

(INSERT TABLE 1)

The second and third paradigms were selected based on existing literature investigating police performance in decision making contexts. Specifically, response inhibition under stress, operationalized as go/nogo (shoot/don't shoot) decision-making, has been linked to increased errorrates with increased threat level (Hashemi et al., 2019, 2021; Nieuwenhuys et al., 2015) Similarly, priming has been shown to increase wrong shooting decisions in police officers primed with a radio dispatch indicating that an upcoming opponent was armed (Taylor, 2019). These two paradigms were implemented in the game in the form of a zombie shooting task (see below).

\subsubsection{The VR Game}

The game scenario unfolded as follows: Participants found themselves in a dimly lit parking garage, received dispatch information about hostile targets with a description of their features, were approached by (friendly and hostile) targets, and decided whether to shoot or not. Each game session lasted approximately 15 minutes. Targets were coming towards the participants from all directions, in fourteen waves. During each wave, the participant would receive dispatch information over the walkietalkie to shoot the hostile but not the friendly targets, including a description of the hostile targets. All targets had two identifying features that made them recognizable as friendly or hostile. The large identifier was their body type (tall male, small male, tall female, or small female). During the game this identifier became less reliable to identify a target, as hostile targets had increasingly more varying 
213 body types (starting with 100\% targets matching the description and decreasing to 50\% in the last

214 waves). The small identifier was their eye color (red, blue, or yellow); this was always $100 \%$ reliable.

215 To summarize: The dispatch information for the eye color of hostile targets would always be correct,

216 but the dispatch information for their body types was not completely accurate. The body type was visible from a far distance, while eye color was only visible when the target had approached to a close distance. Hence, identifying targets with the correct eye color and shooting at them on time was our implementation of the go/nogo task component, while the radio dispatch announcing suspected body types associated with the targeted eye-color was our implementation of the priming component.

Each time the player shot, the game recorded if the shot was a hit or a miss. In case of a hit (i.e., hostile target with correct eye color), the game logged the body type of the target and the distance between the target and the player. Shooting a friendly target (i.e., wrong eye color) was punished by a loud burst of noise. Each time a target reached the player without being shot, the game logged the body type of the target, whether it was hostile and the time that it had spent in the line of sight of the player. Hostile targets would then stay next to the player and attack them until shot. The player was notified of the attack by sound, and a red halo appeared framing their field of view. Players could not "lose" the game in the sense that they reached game-over, the hostile targets had to be all shot before the next wave would start. Please note, in contrast to more traditional laboratory assessments of go/nogo performance, different trial types were here presented at the same time (i.e., multiple targets approached the player at the same time). Hence, time pressure was created by the fact that multiple choices had to be made concomitantly, to simulate a short response window, required to maximize false alarm rates (Young et al., 2017).

At the end of each session, the participant was presented with scores ranging from $0 \%$ to $100 \%$, summarizing their performance on three metrics commonly used to describe police performance in the field: Control over the situation, control over the suspect and control over the self (Binder \& Scharf, 1980; see supplementary material 1 for the formulas used to calculate these scores). While the first two scores represented behavioral elements, the last one was a summary of the breathing pace performance rewarded by the biofeedback. The scores were calculated to make the scores of "control of the situation" and "control of the suspect" relatively easy: Participants could achieve high scores without excessive effort. On the other hand, the "control of the self" score directly represented the physiological control score, thus helping to nudge the players toward focusing on physiological control more in the following sessions.

\subsubsection{Biofeedback parameter and implementation}

245 In sessions in which the biofeedback was displayed to the player (ABBABABABA withdrawal design; $246 \mathrm{~A}=$ without biofeedback: session 1, 4, 6, 8, and 10; $\mathrm{B}=$ with biofeedback: session 2, 3, 5, 7, and 9), a breathing pace of eight breaths per minute was rewarded by having optimal vision, with faster or slower breathing paces being progressively punished by reduced (tunneled) vision (see Figure 1).

\section{(INSERT FIGURE 1)}

\section{Figure 1: Implementation of the biofeedback as peripheral vision modulation.}

The quality of the vision (on the left) was linked to the biofeedback score, calculated from the breathing speed and amplitude (on the right); (A) Vision with a biofeedback score equal to 0 (the player is not breathing at the rewarded pace); (B) example of fast and shallow breathing amplitude, corresponding to a biofeedback score of 0; (C) Vision with a biofeedback score equal to 1 (maximum adherence to rewarded breathing pace) or in A-phase sessions in which online 
biofeedback was not presented to the player; (D) example of slow and deep breathing amplitude, corresponding to a biofeedback score of 1 .

250 The visual feedback on participants' breathing pace was implemented by reducing the vision of the player in the VR task proportionally to their non-adherence to the rewarded breathing pace. This "tunneled" vision served to help the player control their breathing pace in the heat of the moment, when action reduced awareness of their own physiological processes. The biofeedback value was calculated by means of a spectral density estimation and updated at a rate of $.5 \mathrm{~Hz}$, and ranges between 0 and 1 . Hence, every 2 seconds, a breathing segment of the last 30 seconds of breathing data was analyzed, resulting in an overlap of 28 seconds between consecutive segments. It rewarded diaphragmatic breathing at a pace of eight breaths per minute. This target is faster than the six breaths per minute pace recommended by the literature to increase HRV (Ben-Tal et al., 2014; Brown et al., 1993; Hirsch \& Bishop, 1981), as piloting revealed that such a low pace was too hard to achieve in action. The exact signal processing pipeline and data extraction can be found in the supplementary material of our previous article, detailing the development of the biofeedback parameter (Brammer et al., 2021). Importantly, the visual presentation of the biofeedback could be switched off, in which case the player would always have a full vision, independently from their biofeedback score. This parameter was experimentally manipulated between training sessions to test the impact of biofeedback presentation (see procedure section).

\subsubsection{Questionnaires}

All questionnaires were administered in a paper and pencil form. The following questionnaire data were collected.

\subsubsection{Trait-assessments of anxiety}

Participants' trait anxiety was assessed in the first session using the Dutch State-Trait Anxiety Inventory with twenty items and four response options ( 1 = "almost never" to 4 = "almost always"; van der Ploeg, 1984). An example of a statement is "I feel satisfied with myself". A total score was calculated by calculating the sum of all item scores (range 20-80), with higher scores corresponding to less anxiety.

\subsubsection{Prior gaming experience}

Participants' prior gaming experience was assessed in the first session using two self-constructed questions. Participants were asked how many hours a day they played video games on a weekday and how many hours during a day on the weekend. Response options were: 1) I do not play video games; 2) less than one hour per day; 3) one to two hours a day; 4) two to three hours a day; 5) three to four hours a day; 6) more than four hours a day.

\subsubsection{Pre-test questionnaire}

The pre-test questionnaire (target approach analysis, see supplementary material 2) is a short selfconstructed questionnaire inspired by questionnaires used to investigate plan-making in real-life policing situations (Adang \& Timmer, 2005), administered before each VR session to the players. They were asked to indicate which one of the three control scores mentioned above they would focus on, what scores they expected to achieve as well as the scores they expected their colleagues to achieve. An open question concluded the questionnaire, to ask the player if they had a specific strategy in mind 
for the upcoming session. The aim of this questionnaire was twofold: Measuring the participants' training intentions and prime them to enter the game in a "police" mindset.

\subsubsection{Post-test questionnaire}

After each session, the post-test questionnaire (after action report, see supplementary material 2), a short self-constructed questionnaire, was administered to the participants. The players were asked to indicate which score they thought they had achieved and several open-ended questions to make them think about their performance. The aim of this questionnaire was twofold: Measuring the participants' performance estimates, and maintain a "police" mindset.

\subsubsection{Threat and challenge appraisal}

Participants' appraisal of threat and challenge during the game was assessed after each session on an eleven-item scale developed by Mendes et al. (2007), with seven response options per item ( $1=$ "totally disagree" to 7 = "totally agree). Six items were indicative of the threat aspect (i.e., "this task is demanding," " $\ldots$ is stressful," “ $\ldots$ is distressing," “... is threatening"; "I am uncertain how I will perform"; "this task requires a lot of effort"). In addition, five items were indicative of perceived positive challenge (i.e., "I have the abilities to perform well," "Ihave the expectations to perform well," "performing well is important to me," "this task is a positive challenge," and "I am the type of person who does well on these tasks"). Two distinct scores (ranging from 1 to 7) were calculated for the threat and the challenge aspect, by averaging the related item scores.

\subsubsection{Engagement}

Participants' engagement was assessed after each session using seven items from the Intrinsic Motivation Inventory with seven response options ( $1=$ "totally disagree" to $7=$ "totally agree) (Center for Self-determination Theory, 2019; McAuley et al., 1989). An example statement is: "I would describe this activity as very interesting". The negatively formulated statements ("I thought this was a boring activity" and "This activity did not hold my attention at all") were recoded. A total score was calculated by averaging the scores on all items (range 1 to 7 ). The higher the score, the higher participants' engagement during the training.

\subsubsection{Procedure}

After giving written informed consent and filling in the questionnaire about gaming experience on the first session, each session consisted of participants putting on the respiration belt and the heart-rate belt, receiving a police vest, the controllers (radio and gun in the VR environment), headphone, and VR headset. Next, participants filled in the pre-test questionnaire, standing, while their physiological baseline was measured. The participants then performed the VR task for around 15 minutes until they completed all the waves of the game.In the first session, participants first played a tutorial in which they were instructed about processes such as confirming a radio message, followed by the actual VR task. The tutorial was also present in the second session, with additional information about biofeedback control and a breathing pace training. From session two onward, participants were instructed to breathe five seconds in and five seconds out while playing. After playing each session, participants filled in the rest of the questionnaires regarding their appraisals of the game. When the participant finished all questionnaires, they were presented with their average session scores of control over the situation, suspect and self.

To allow statistical inferences in small sample sizes, in this single case experimental design (SCED) study participants were invited ten times to the training sessions. A withdrawal ABAB design was used in which the experimentally withdrawn variable was the presence of online biofeedback on the 
participant's breathing pace, where slow and deep breathing was rewarded. The online biofeedback was presented to the participants by means of vision impairment while performing the VR task. Over the course of one month (September 2020), all participants completed the ten sessions (phases) following a withdrawal design (ABBABABABA). The majority of the sessions were separated from each other by one to five days. Due to participant scheduling limitations, some sessions had however to be done in the same day. In such a case, the first session always was an A phase, to prevent short term carry-over from the biofeedback presentation, displayed in B phases. Continuous breathing-based biofeedback was added in the B-phases and withdrawn in the A-phases. The design is in line with the guidelines for small-N designs, by allowing a minimum of four repetitions of the addition-withdrawal procedure (Kratochwill et al., 2013).

\subsubsection{Data preparation}

Any identification information was removed from participant data and the data were securely stored on password-protected servers hosted by the Radboud University. The data was only accessible for approved members of the research team. The research data was not shared with the police organization, nor with the IBT center from which participants were recruited.

\subsubsection{Physiological recordings}

The physiological data (breathing-based biofeedback score and inter-beat ' $R-R$ ' intervals) were automatically saved at a rate of $.5 \mathrm{~Hz}$. The data points were then synchronized with the game events and averaged before the start of the game to constitute the baseline. Since the baselines were inconsistent in length, the shortest recording ( 29 samples $=56$ seconds) was used as a length reference, hence we only considered the last 29 samples portion for longer baselines. Per session, the inter-beat $(\mathrm{R}-\mathrm{R})$ intervals were interpolated to extract low $(.04 \mathrm{~Hz}$ to $.15 \mathrm{~Hz})$ and high $(.15 \mathrm{~Hz}$ to $.4 \mathrm{~Hz})$ frequency HRV, the low/high frequency ratio of HRV, and the coherence between the low frequency HRV and breathing. The low frequency coherence metric is extracted as an index of relaxation, as Hayano and Yuda (2019) suggested that breathing induced fluctuations in the low frequency spectra of HRV reflects the presence of resting function. The scripts used to extract those HRV metrics can be found on GitHub (Brammer, 2020) and were taken from the guidelines proposed by Shaffer and Ginsberg (2017).

\subsubsection{Decision-making and response inhibition behavior}

In-game events and actions were summed within a session to compute accuracy and signal detection measures. Hit scores were calculated by adding events where the participant shoots at an incoming hostile target before it reaches the player. Similarly, miss scores were the sums of hostile targets reaching the player before being shot, correct rejection scores were the sums of friendly targets reaching the player unharmed and finally false alarm scores were the sums of friendly targets being shot by the player. For each of those scores, we also recorded if the target involved in the event had the primed large identifier (body type announced by the radio dispatch as potentially hostile).

\subsubsection{Data analysis}

\subsubsection{Missing and excluded data}

Due to a technical issue with the heart rate belt recordings, the HR data of session 1 was missing for participants 3 and 5, although the participants did complete the training session. Moreover, due to material failure with the breathing belt used for biofeedback, the breathing data of session 8 was missing for participant 4 , although the participant completed the full training session. Subject 9 was 
excluded from HRV-related analyses, since his high frequency component of HRV was more than 3 standard deviations higher than the rest of the group, for several sessions; this was due to a lack of accuracy in the $\mathrm{R}$ peak detection from the heart rate belt. This problem did not affect biofeedback measurements.

\subsubsection{Environment design validation}

Due to the small sample size, this section of the results is purely descriptive, as only the biofeedback data allowed to make meaningful statistical inferences thanks to the withdrawal (ABBABABABA) design.

\subsection{Game arousal, challenge, and engagement}

To descriptively assess, for each subject, the evolution of the level of arousal, challenge and engagement, individual trajectories were plotted alongside group average. For the HR, average baseline and in-game session scores were obtained. The in-game scores were obtained by subtracting the average baseline score.

\subsection{Biofeedback relevance}

To assess whether our biofeedback manipulation was successful in influencing HRV, the average biofeedback score within a session was correlated with the low and high frequency components of HRV and with the coherence between the breathing and low frequency HRV. The latter correlation is used to measure the extent to which low frequency HRV is influenced by deep breathing, an indicator of resting function rather than sympathetic dominance (Hayano \& Yuda, 2019). Since correlations were based on all 10 sessions of eight participants in total, where each session is a data point, we used a repeated measure correlation approach using the R package "rmcorr" (Bakdash \& Marusich, 2017, 2021). Subject 9 had to be excluded from those analyses due to a measurement error.

To measure how awareness of the breathing control performance evolved over the course of the 10 sessions, we computed for each session the difference between participants' self-rating in breathing performance and the actual session score (real score - self rating) ${ }^{1}$.

To further investigate the relevance of biofeedback, we looked at how often players mentioned breathing (e.g., "I need to focus more on the breathing"), biofeedback visual impairment (e.g., "Too much tunnel vision") and self-control score (e.g., "Focus on self-control") in the open-ended questions asked to the player before and after the VR task. Mentions of action-related elements (e.g., "Reload more often" or "Monitor 360") were scored as well.

\subsection{Decision-making behavior}

To measure decision-making (shoot/don't shoot) performance, we calculated the amount of hits, misses, correct rejection and false alarms per subject and session. Additionally, sensitivity $\left(d^{\prime}=\right.$ $[\mathrm{z}($ Hit rate $)-\mathrm{z}($ False alarm rate $)]$ and response bias (criterion $=-[\mathrm{z}($ Hit rate) $\mathrm{z}$ (False alarm rate)]/2) were computed according to signal detection theory (McFall \& Treat, 1999). Since some participants managed to avoid false alarms for an entire session, a loglinear correction was applied to the data to avoid infinite values (Hautus, 1995; Stanislaw \& Todorov, 1999). To describe 
the effect of the priming, we calculated per session and subject the difference in false alarm rate between targets that had the body type primed by radio dispatch and those who did not ${ }^{1}$.

\section{$412 \quad$ 2.2.8.3 Training efficiency: physiological control}

413 Next, we tested the link between the presentation of online biofeedback in B-phases and the 414 improvement in breathing control in action witnessed in all subjects. Since multiple datapoints can be extracted per session, this part of the study allows for inferential statistics, according to the SCED methodology (Kratochwill et al., 2013). Multiple datapoints were extracted per session: The biofeedback values of a session were separated in 15 second bins and averaged for each bin. The biofeedback scores of individual participants were analyzed within and between sessions (A-sessions, B-sessions, B-A-sessions, and A-B sessions). The six features of the SCED visual analysis were level, trend, variability, immediacy of effect, consistency of data patterns across similar phases and degree of overlap of data (Kratochwill et al., 2013). A change of the data-patterns when there was a change in condition (addition or removal of biofeedback) indicates the biofeedback had an effect. To determine whether there was a significant intervention effect for a participant, a minimum of three such changes was needed for at least three of the six features (Horner et al., 2005; Kratochwill et al., 2013; Lane \& Gast, 2014). Additional descriptive representations of HRV parameters were included in this section, since the main goal of breathing-based biofeedback was to calm participants by regaining parasympathetic dominance through HRV increase.

\subsection{SCED analysis}

To illustrate the within and between session dynamics, the evolution of the biofeedback scores, evaluated at the 15 second bin level throughout the entire training, were plotted for each subject along with separated fitted trend lines for the A and the B phases. The trend lines were obtained with the MATLAB function "polfit.m". To increase visibility of the data, the lines were smoothed with the moving average option of the MATLAB function "smooth.m". Since the biofeedback score was measured on a time window of 30 seconds, the first two data bins of each session were discarded to avoid analyzing data from the baseline period.

Of the six SCED features used to test the role of biofeedback, data overlap is the one presented in the result section as it is most relevant to our design. For completeness, we report other aspects in the supplementary material 6 . To test whether vision impairment was a salient enough way of providing biofeedback in B-sessions, and causally influenced the player's behavior, data overlap of the biofeedback values of consecutive sessions was calculated by using the Kendall's tau ranked correlation coefficient (Kendall, 1938). For each subject, the tau scores were then aggregated into two distinct scores (addition and removal) by combining effects of single contrasts (Manolov et al., 2015; Tarlow, 2017a, 2018). The addition score encompasses the tau scores for A-to-B phases contrasts, hence when comparing consecutive sessions where the first is played without online biofeedback and the second with biofeedback. Conversely, the removal score encompasses the tau scores for B-to-A phases (transition from with to without biofeedback). Kendall's tau was extracted by using an edited version of the R code by Tarlow (2017). The editing consisted in removing Theil-Sen estimator used for baseline trend correction (Tarlow, 2017b). Baseline trend correction was not used for this dataset, as trend analysis revealed that a within session trend was often present but negative, hence correcting for it would lead to false positive results.

${ }^{1}$ Individual trajectories were plotted alongside the average of all participants, with standard error. 


\subsection{Environment design validation}

\subsubsection{Does the VR-game environment evoke arousal and engagement?}

The VR-game elicited psychophysiological arousal and was experienced as challenging and engaging. This is indicated by the self-reported threat and challenge appraisals, the increase in HR and the selfreported engagement score (see Figure 2A to 2C). As expected, police officers reported consistently low levels of experienced threat, with an average of 2.39 on a 7 point scale $(S D=.86$; see supplementary material 4) over all sessions and participants. However, challenge scores were consistently high (Figure 2A) indicating that the participants experienced the game as positively stimulating $(M=5.36, S D=.65)$. In terms of absolute HR during the sessions, the average was 79 BPM. There was a marked peak in HR during the first session $(M=99 \mathrm{BPM})$ with substantial variation between subjects from $M=78 \mathrm{BPM}$ (for subject 4) to $M=176 \mathrm{BPM}$ (for subject 1). This strong variability was only witnessed for the first session. Relative to the baseline period immediately preceding the game start, an average increase of HR from baseline of approximately 10 BPM was observed (Figure 2B), similar to increases witnessed in established stress induction protocols (e.g. see Vogel et al., 2015). As shown in Figure 2B also participants' reported engagement (scale 1-7) was generally high $(M=5.65, S D=.66)$, steadily decreasing until session seven, where the average engagement was still 5.3, corresponding to a moderately high level of engagement.

\section{(INSERT FIGURE 2)}

Figure 2: Stability of arousal and engagement during the course of the training. Changes across the whole training in: (A) self-reported challenge ( $1=$ very low to $7=$ very high); (B) mean engagement ( $1=$ very low to 7 = very high); (C) HR change, in BMP, from the 30 s pre-test baseline (the dashed line represents a null change); (D) Difference between the self-reported estimation of biofeedback control score after the VR task and the real score (range 0 to $100 \%$; plotted value $=$ real score - reported score). Stderr $=$ standard error of the mean; BFB ON $=$ Sessions in which online biofeedback was presented to the participants.

\subsubsection{Does the biofeedback implementation influence HRV and facilitate physiological awareness?}

A strong and significant positive relation was found between the average biofeedback score and the coherence between low-frequency HRV and respiration in a session $(\mathrm{r}(68)=.72, p<.001)$. A smaller positive correlation was also found for low frequency HRV $\left(\mathrm{r}_{\mathrm{s}}(68)=.47, p>.001\right)$ but not for high frequency HRV $\left(\mathrm{r}_{\mathrm{s}}(68)=.15, p=.212\right)$. Hence, biofeedback scores correlated strongly with breathing induced fluctuations in HRV, a resting function index (Hayano \& Yuda, 2019; Shaffer et al., 2014).

To evaluate the participants' self-awareness of physiological control during the training process, the differences between the self-rating of physiological control and the objective biofeedback score are plotted in Figure 2D. A fast reduction in differences (overestimation) can be seen in the first half of the training process, with a notable yet short-lived increase in difference once online biofeedback was 
482

483

484

485

486

487

488

489

490

491

492

493

494

495

496

497

498

499

500

\section{(INSERT FIGURE 3)}

Figure 3: Behavioural metrics (in-game). (A) Go/nogo action distributions across sessions and subjects. Columns are sub-divided according to the large identifier of the target related to the trial. (B) $d$ ' from signal detection theory indicating sensitivity to target type (hostile/friendly); (C) criterion from signal detection theory indicating potential changes in strategy (D) Difference score of false alarm depending on the body type (primed body type - unprimed body type); Hit = hit; CR $=$ correct rejection; $\mathrm{FA}=$ false alarm; Miss = misses $;$ large ID = has the primed body type, announced as presumably hostile in radio dispatch; other ID $=$ does not have a body type announced as presumably hostile in radio dispatch; BFB on $=$ Sessions in which online biofeedback was presented to the participants; Stderr $=$ standard error.

\subsection{Training validation}

\subsubsection{Biofeedback score}

The average biofeedback scores per participant are depicted in Figure 4A. The overall biofeedback score was $M=.077(S D=.16)$ in the first session $\left(\mathrm{A}_{1}\right)$, increasing to $M=.497(S D=.279)$ across all sessions with online biofeedback (B phases) and to $M=.460(S D=.266)$ across the subsequent sessions 


\subsubsection{Evolution of HRV}

511 We here illustrate how beneficial the breathing-based biofeedback training is to influence HRV through RSA modulations. In Figures 4B to 4D the evolution of the low and high frequency components of HRV, and the coherence between low frequency HRV and the breathing pace are presented. While the low frequency HRV-breathing coherence (Figure 4C) parallels the increase over time shown by the biofeedback score, displayed in Figure 4A, quite accurately, this pattern is less apparent for low (Figure 4D) or high (Figure 4B) frequency HRV. This indicates that our operationalization of the biofeedback parameter as a paced breathing reward successfully promoted higher coherence between the breathing and the HR (Schwerdtfeger et al., 2020; Shaffer et al., 2014), an index of resting function (Hayano \& Yuda, 2019).

(INSERT FIGURE 4)

Figure 4: Evolution of the biofeedback score and the HRV indexes

Changes across the whole training in (A) the average biofeedback score; (B) the high frequency component of HRV (.15Hz to .4Hz); (C) the coherence between the low frequency HRV and breathing; (D) the low frequency component of $\mathrm{HRV}(.04 \mathrm{~Hz}$ to $.15 \mathrm{~Hz})$. BFB ON $=\mathrm{B}$ phases, where online biofeedback was presented; Stderr $=$ Standard Error; LF-breathing coherence $=$ coherence between the low frequency component of HRV and breathing; LF HRF = low frequency HRV.

\subsubsection{SCED analysis}

The within and between session evolution of each participant's biofeedback score (indicative of breathing control) is presented in Figure 5. Trend lines revealed that every subject showed a positive trend with increasing biofeedback scores over time for both A and B phases, except subject 4 who showed no improvement in the B phases (red lines). Subjects 1, 3 and 5 displayed a particularly steep learning pace. Interestingly, those are also the subjects with a higher biofeedback average in A-phase sessions than in the B-phase ones.

\section{(INSERT FIGURE 5)}

\section{Figure 5: Evolution of the biofeedback score across the entire training period.}

Each datapoint represents the average biofeedback value for a 15 seconds epoch. Scores range from 0 (no adherence to the rewarded breathing pace) to 1 (perfect adherence to the rewarded breathing pace). $\mathrm{B}$ phase $=$ breathing score for $\mathrm{B}$ phase sessions (Session 2, 3, 5, 7 and 9); $\mathrm{A}$ phase = breathing score for A phase sessions (Session 1, 4, 6, 8 and 10); B fit = fitted line for the B phase sessions; A fit $=$ fitted line for the A phase sessions. 


\subsubsection{Data overlap}

530 To assess the influence of the biofeedback presence (on or off), changes in breathing biofeedback score were related to the addition or removal of biofeedback by means of Kendall's tau (Table 2). Results indicated a consistent positive effect of the addition of online biofeedback across subjects (A to B phase). Out of 36 individual transitions where biofeedback was added, 25 transitions were found to be positive and significant, with four subjects (2, 5, 8, and 9) each having three significant effects of nonoverlap and a significant meta-effect when all A-to-B contrasts were merged, thus reaching formal criteria for a significant intervention effect. Importantly however, all nine subjects showed an effect in the same positive direction (Table 2). This suggests that, while there was a difference in the robustness of learning, participants generally improved in physiological control when online biofeedback was presented. Upon removal of biofeedback (B to A-phase), the pattern was more mixed. Out of 36 removal transitions, 14 transitions were found to be significantly negative. Only subjects 8 and 9 showed three significant repetitions of non-overlap, and only subject 9 had a significant meta-effect of withdrawal with in total six out of nine subjects showing a negative effect. Overall, the results support a causal effect of the biofeedback experimental manipulation, with seven participants $(1,2,5,6,7,8$, and 9) showing a minimum of three significant non-overlap effects in the expected direction (Kratochwill et al., 2013). More elaborate SCED analyses can be found in the supplemental material (supplementary material 6), which according to formal SCED guidelines together indicated a moderate positive effect of our training procedure (Kratochwill et al., 2013).

\section{Discussion}

We aimed to validate the design of a novel biofeedback training tool for in-action physiological regulation in police. From a design perspective, we found that the VR game was successful in creating an engaging, challenging, and arousing environment. Our in-game biofeedback implementation succeeded in improving physiological awareness. Moreover, behavioral metrics of performance indicated suitability for probing response inhibition and priming effects under stress. From a training perspective, we additionally found support for the trainability of deep-breathing by presenting biofeedback in-action. These results, while preliminary given the small sample, suggest the feasibility and promise of influencing physiological control in an action context with tools like our new VR biofeedback application.

One of the rationales for using a VR context to train physiological control was the possibility to evoke strong emotions (Parsons, 2015). As expected, self-reports indicated a high sense of positive challenge, but a low sense of threat. This result indicates that the game is a good learning environment as it is not perceived as too threatening (Jamieson et al., 2013), although this interpretation should be cautious given the tendency of police officers to underreport socially undesirable emotions (Habersaat et al., 2021; McCanlies et al., 2014). One additional possible explanation for the low threat score, as pointed out by Weerdmeester et al. (2020), is that the high level of challenge experienced by the participants throughout the training could partially be explained by the effect of biofeedback, which has been theorized to help participants better appraise threat into challenge since interoceptive signals of stress are dampened.

In terms of arousal, elicitation was successful in our VR environment as in-game HR increases from baseline were comparable to established stress induction protocols (Boesch et al., 2014; Vogel et al., 2015). However, we cannot establish the extent to which this arousal is of emotional nature or due to 
al. (2011) showed effects of similar magnitude from exposure to a VR environment without participant movement. Here again, the effect of biofeedback should also be taken into account: the slow abdominal breathing promoted by the addition of biofeedback has a heart-rate reducing effect (Russo et al., 2017), which may dampen the arousing effect of the VR environment.

We used VR to maximize the sense of engagement experienced by the participants, as it has been highlighted as an important nonspecific factor fostering behavioral change (Holzinger et al., 2006). Engagement also helps with accurate recollection of the participant's physiological arousal (McCall et al., 2015), thus improving biofeedback learning. The high and lasting engagement in our sample may be ascribed to the advantages of VR (Riva et al., 2007), but could also be partially explained by peer pressure to perform, as our participants were, on their own initiative, actively comparing their performance scores with each other, a common practice in the police forces (Chen et al., 2013). This behavior provides support to the idea that reporting police-relevant scores at the end of each session helps strengthen engagement.

Just as the scores helped the participants to engage in the training, it also helped them to better estimate their performance and enhance physiological awareness, as illustrated by the improvements in physiological scores estimation (see Figure 2D). Similarly, the integration of biofeedback as peripheral view modulation was successful in eliciting awareness of breathing. This "tunneled vision" is known to be a relatable phenomenon for police officers (Dirkin, 1983; Klinger \& Brunson, 2009). Indeed, as shown by the participant's written reports before and after action, mentions of breathing-related elements increased throughout the training.

Regarding the behavioral metrics, despite the small sample, we could show that behavioral measurements were suitable for individual performance indexes to be extracted, per session. It is worth noticing that decision-making stably improved throughout the training. Analyses of the mistakes showed preliminary evidence that priming the participants for certain targets' body types increased the chance for friendly targets to get shot when their body type partially matched the description, which is in line with priming tests performed in more realistic setups on police officers (Taylor, 2019). The game environment may therefore be suitable to investigate, in future studies, the in-action relation between physiology and response inhibition, as well as the effect of biofeedback on performance (Caballero Sánchez et al., 2016). Ideally, associations between in-game behavior and external measures of response inhibition under stress should be demonstrated to further establish the validity of the in game behavioral assessments. Importantly, performance was affected by the biofeedback. Biofeedback was implemented as vision manipulation and thus could impair shooting and target recognition. This impairment created an artificial link between physiological control and behavioral performance. This is illustrated by fact that the sensitivity $d$ ' index tended to reduce in sessions with biofeedback. This confound, together with the changes in game difficulty during a session and the small sample available, made it difficult to investigate links between physiology and performance as have been previously reported (Hashemi et al., 2019). It is however worth noticing that subject 5, the participant with the highest behavioral performance scores, was also the one with the highest biofeedback score in sessions without biofeedback. This transfer of physiological control skill suggests that successful transfer of breathing control skill did not come at the cost of reduced performance.

613 One of the main contributions of the current study was to investigate the trainability of breathing 614 biofeedback in an action context. Our results suggest that despite the fact that our subjects all received 615 breathing-biofeedback in a classroom setup in the years preceding our experiment, no subject seemed 616 able to control their breathing to satisfying levels prior to the introduction of in-action biofeedback. 617 Additionally, our results show support for the in-action trainability of deep breathing, thus extending 
618 previous evidence showing deep breathing trainability in passive VR contexts (Rockstroh et al., 2019), 619 but also in breaks during real-life police training scenarios (Judith Pizarro Andersen et al., 2018). 620 Trying to apply emotion regulation techniques in-action is not a new idea, and has been implemented 621 with techniques like neurofeedback (Schoneveld et al., 2016), and even breathing biofeedback (Bossenbroek et al., 2020), albeit in a rather meditative VR context. To the best of our knowledge, this is the first attempt at rewarding deep breathing while immersed in an arousing action context. Additionally, only a few participants reached a plateau in biofeedback training after ten sessions. It is therefore unclear when the training benefits of such technique would stop. This issue should be investigated in future research, since there are institutional pressures to shorten training for police officers, sometimes to the point of rendering them useless (Di Nota et al., 2021).

Importantly, although the deep breathing in action was shown to reliably increase due to biofeedback, one limitation of this study is that a positive effect of the training on parasympathetic dominance indices could not be unambiguously demonstrated and should be further investigated in future studies. We did identify a potentially strong link between adherence to the required breathing pace and a resting function index (the coherence between breathing and low-frequency HRV), as well as with an index of low-frequency HRV. We found no association for high-frequency HRV, which has been linked to increased performance in decision tasks (Gamble et al., 2018) and is usually seen as an index of parasympathetic dominance. The lack of results in high-frequency HRV might have a methodological explanation, as standing has been reported to dampen this HRV metric (Srinivasan et al., 2002). Additionally, training deep breathing transfers the breathing-induced HRV fluctuations from the higher to the lower part of the spectrum, hence increasing low-frequency HRV, possibly at the cost of highfrequency HRV (Hayano \& Yuda, 2019). While low-frequency HRV may in fact be driven by parasympathetic nervous system activity during slow breathing (Kromenacker et al., 2018; Schwerdtfeger et al., 2020) it does not allow claims about the influence of the parasympathetic nervous system. Moreover, we found no consistent increase in either low or high frequency HRV across out training, only in coherence. While coherence has been linked to improved cognitive and emotional function (Mather \& Thayer, 2018; Schwerdtfeger et al., 2020), it is not possible, with the current dataset, to assess if the specific effect we report here is effective in producing such cognitive and emotional improvements.

The present study has other limitations, mostly due to the small sample size, which prevents not only inquiries on efficiency and training output (Smith \& Little, 2018), but also on the interaction between behavior and physiology. A larger and more diverse sample, combined with a non-VR transfer task, 650 would allow us to test the extent to which the training in VR transfers to physiological and behavioral patterns observed in real life, which is a critical test to evaluate the generalizability of the VR measures (Miller et al., 2019).

In terms of future work, our VR game could also be used to investigate the dynamical interaction between physiological state and decision-making in a more complex and engaging environment than traditional laboratory assessments. Indeed, little is known about the effectiveness of physiological control in the variety of phases through which police action evolves. While a fully realistic VR setup would contain too much variability and dimensions to measure performance reliably (Brehmer, 1992; Michela et al., 2019), testing well-known scientific measurements of decision-making in dynamical interactions could prove invaluable to relate performance and physiological control, but also to further investigate the external validity of those paradigms (Flake et al., 2017).

661 To conclude, while the generalizability of the results presented here needs to be assessed in future 662 studies with larger samples, the present study showed the promise of a VR game to train physiological 
663 regulation in an arousing, police-relevant decision-making context. In addition, there seems to be 664 support for targeting the behavioral action mechanisms that were included in the VR game. Our VR 665 design opens new potential avenues for testing the impact of priming, arousal, and physiological 666 control on (police-relevant) behavior in a more naturalistic context than traditional laboratory 667 experiments. It will be important to design future studies to not only assess whether the VR game 668 impacts decision-making under stress for police officers, but also if the physiological mediators of 669 these effects are indeed the same that are targeted in the training. 


\section{Tables}

\section{Table 1.}

Operationalization of in-game tasks.

\begin{tabular}{|c|c|c|c|c|}
\hline $\begin{array}{l}\text { Experiment } \\
\text { al paradigm }\end{array}$ & $\begin{array}{c}\text { In-game } \\
\text { operationalization }\end{array}$ & $\begin{array}{l}\text { In-game } \\
\text { mechanic }\end{array}$ & $\begin{array}{c}\text { Game output / } \\
\text { proximal measure }\end{array}$ & $\begin{array}{l}\text { Training } \\
\text { outcome }\end{array}$ \\
\hline $\begin{array}{l}\text { Emotion } \\
\text { regulation }\end{array}$ & Biofeedback & $\begin{array}{l}\text { Width of the field } \\
\text { of view linked to } \\
\text { breathing pace }\end{array}$ & $\begin{array}{l}\text { Breathing } \\
\text { control and } \\
\text { HRV scores }\end{array}$ & $\begin{array}{c}\text { Physiological } \\
\text { control }\end{array}$ \\
\hline $\begin{array}{l}\text { Response } \\
\text { inhibition } \\
\text { (Go/NoGo) }\end{array}$ & Shoot/don't shoot & $\begin{array}{c}\text { Shooting at } \\
\text { targets matching } \\
\text { dispatch } \\
\text { information }\end{array}$ & Accuracy & $\begin{array}{l}\text { Response } \\
\text { control }\end{array}$ \\
\hline Priming & Dispatch bias task & $\begin{array}{c}\text { Targets' } \\
\text { (mis)match with } \\
\text { dispatch } \\
\text { information (body } \\
\text { shape; eye color) }\end{array}$ & $\begin{array}{c}\text { Accuracy based } \\
\text { on body type of } \\
\text { the target }\end{array}$ & Bias resistance \\
\hline
\end{tabular}

Note. Model for the incorporation of experimental paradigms in the game environment;

$\mathrm{HRV}=$ Heart-rate variability. 
Table 2. Kendall's tau non-overlap indices for consecutive sessions

\begin{tabular}{|c|c|c|c|c|c|c|c|c|c|c|}
\hline \multirow[t]{3}{*}{ Subject } & \multicolumn{10}{|c|}{ Kendall's tau } \\
\hline & \multicolumn{5}{|c|}{ Addition (A-to-B phase contrast) } & \multicolumn{5}{|c|}{ Removal (B-to-A phase contrast) } \\
\hline & $\mathrm{S} 1-\mathrm{S} 2$ & S4-S5 & S6-S7 & S8-S9 & Meta & S3-S4 & S5-S6 & S7-S8 & S9-S10 & Meta \\
\hline 1 & $.8 * * *$ & -.13 & $.21 * *$ & -.01 & .26 & $.21 * *$ & $.27 * * *$ & $-.16 *$ & .03 & .09 \\
\hline 2 & $.67 * * *$ & $.16^{*}$ & $.47 * * *$ & $.29 * * *$ & $.42 *$ & -.09 & $-.3 * * *$ & -.12 & -.1 & -.15 \\
\hline 3 & $.53 * * *$ & $.25 * * *$ & .08 & .06 & .25 & -.04 & .02 & 0 & $.17 *$ & .04 \\
\hline 4 & $.6 * * *$ & $.35 * * *$ & $-.23 * *$ & $N a N$ & .26 & $-.4 * * *$ & -.12 & $N a N$ & -.05 & -.19 \\
\hline 5 & $.62 * * *$ & $.37 * * *$ & $.17 *$ & $.35 * * *$ & $.40 *$ & $-.26 * * *$ & -.01 & .1 & $.17 *$ & .004 \\
\hline 6 & $.52 * * *$ & $.14^{*}$ & .11 & 0 & .21 & -.04 & $-.17 *$ & .06 & $-.24 * *$ & -.09 \\
\hline 7 & $.47 * * *$ & -.03 & .12 & $.29 * * *$ & .22 & -.05 & .13 & $-.17 *$ & -.09 & -.04 \\
\hline 8 & $.62 * * *$ & $.39 * * *$ & $.25 * * *$ & $.22 * *$ & $.39 *$ & $-.34 * * *$ & $-.3 * * *$ & -.02 & $-.24 * *$ & -.22 \\
\hline 9 & $.56 * * *$ & $.61 * * *$ & -.02 & $.49 * * *$ & $.43 * *$ & $-.43 * * *$ & $-.19 *$ & $-.23 * *$ & $-.55 * * *$ & $-.35 *$ \\
\hline
\end{tabular}

$* p<.05 . * * p<.01 . * * * p<.001$

Note. Grey cells indicate significant non-overlap between two consecutive sessions; i.e., $\mathrm{S} 1-\mathrm{S} 2=$ contrast between the first and the second session (the same applies for the other headings); Meta= Overall effect, obtained by merging the effect-sizes of the single contrasts. 673 
Actie ZeeHond. (n.d.). Retrieved July 30, 2021, from https://www.actievoorgeleidehonden.nl/campagne/actie-zeehond

Adang, O., \& Timmer, J. (2005). Beheersing van Gevaar; Praktijkboek voor de opleiding van vuurwapendragenden en de toetsing van geweldstoepassing. In Reed Business, Reed elsevier.

Allcoat, D., Greville, W. J., Newton, P. M., \& Dymond, S. (2015). Frozen with fear: Conditioned suppression in a virtual reality model of human anxiety. Behavioural Processes, 118, 98-101. https://doi.org/10.1016/j.beproc.2015.06.011

Andersen, Judith P., \& Gustafsberg, H. (2016). A Training Method to Improve Police Use of Force Decision Making: A Randomized Controlled Trial. SAGE Open, 6(2). https://doi.org/10.1177/2158244016638708

Andersen, Judith Pizarro, Di Nota, P. M., Beston, B., Boychuk, E. C., Gustafsberg, H., Poplawski, S., \& Arpaia, J. (2018). Reducing lethal force errors by modulating police physiology. Journal of Occupational and Environmental Medicine, 60(10), 867-874. https://doi.org/10.1097/JOM.0000000000001401

Arnsten, A. F. T. (2015). Stress weakens prefrontal networks: Molecular insults to higher cognition. In Nature Neuroscience (Vol. 18, Issue 10, pp. 1376-1385). Nat Neurosci. https://doi.org/10.1038/nn.4087

Bakdash, J. Z., \& Marusich, L. R. (2017). Repeated measures correlation. Frontiers in Psychology, 8(MAR), 456. https://doi.org/10.3389/fpsyg.2017.00456

Bakdash, J. Z., \& Marusich, L. R. (2021). CRAN - Package rmcorr. https://cran.rproject.org/web/packages/rmcorr/

Batista, D., Silva, H., \& Fred, A. (2017). Experimental characterization and analysis of the BITalino platforms against a reference device. Proceedings of the Annual International Conference of the IEEE Engineering in Medicine and Biology Society, EMBS, 2418-2421. https://doi.org/10.1109/EMBC.2017.8037344

Ben-Tal, A., Shamailov, S. S., \& Paton, J. F. R. (2014). Central regulation of heart rate and the appearance of respiratory sinus arrhythmia: New insights from mathematical modeling. Mathematical Biosciences, 255(1), 71-82. https://doi.org/10.1016/j.mbs.2014.06.015

Binder, A., \& Scharf, P. (1980). Violent Police-citizen Encounter. Annals of the American Academy of Political and Social Science, 452, 111-121. https://www.ojp.gov/ncjrs/virtuallibrary/abstracts/violent-police-citizen-encounter

Boesch, M., Sefidan, S., Ehlert, U., Annen, H., Wyss, T., Steptoe, A., \& La Marca, R. (2014). Mood and autonomic responses to repeated exposure to the Trier Social Stress Test for Groups (TSSTG). Psychoneuroendocrinology, 43, 41-51. https://doi.org/10.1016/j.psyneuen.2014.02.003 
and Disruptive Classroom Behavior: Single-Case Study. JMIR Mental Health, 7(3), e16066. https://doi.org/10.2196/16066

Bouchard, S., Bernier, F., Boivin, É., Morin, B., \& Robillard, G. (2012). Using biofeedback while immersed in a stressful videogame increases the effectiveness of stress management skills in soldiers. PLoS ONE, 7(4). https://doi.org/10.1371/journal.pone.0036169

Bouchard, S., Guitard, T., Laforest, M., Dumoulin, S., Boulanger, J., \& Bernier, F. (2012). The Potential of Stress Management Training as a Coping Strategy for Stressors Experienced in Theater of Operation : A Systematic Review. Post Traumatic Stress Disorders in a Global Context, 271-286.

Brammer, J. C. (2020). biofeedback_analyses/hrv_utils.pyat c9b2ffd067d2e9197c5750f0ae7749ebb7918366 · JanCBrammer/biofeedback_analyses . GitHub. https://github.com/JanCBrammer/biofeedback_analyses/blob/c9b2ffd067d2e9197c5750f0ae774 9ebb7918366/biofeedback_analyses/analysis_utils/hrv_utils.py\#L112

Brammer, J. C., van Peer, J. M., Michela, A., van Rooij, M. M. J. W., Oostenveld, R., Klumpers, F., Dorrestijn, W., Granic, I., \& Roelofs, K. (2021). Breathing Biofeedback for Police Officers in a Stressful Virtual Environment: Challenges and Opportunities. Frontiers in Psychology, 12, 586553. https://doi.org/10.3389/fpsyg.2021.586553

Brehmer, B. (1992). Dynamic decision making: human control of complex systems. Acta Psychologica, 81(3), 211-241. https://doi.org/10.1016/0001-6918(92)90019-A

Brown, T. E., Beightol, L. A., Koh, J., \& Eckberg, D. L. (1993). Important influence of respiration on human R-R interval power spectra is largely ignored. Journal of Applied Physiology, 75(5), 2310-2317. https://doi.org/10.1152/jappl.1993.75.5.2310

Caballero Sánchez, C., Barbado Murillo, D., Davids, K., \& Moreno Hernández, F. J. (2016). Variations in task constraints shape emergent performance outcomes and complexity levels in balancing. Experimental Brain Research, 234(6), 1611-1622. https://doi.org/10.1007/s00221016-4563-2

Chen, H.-C., Chou, F. H.-C., Chen, M.-C., Su, S.-F., Wang, S.-Y., Feng, W.-W., Chen, P.-C., Lai, J.Y., Chao, S.-S., Yang, S.-L., Tsai, T.-C., Tsai, K.-Y., Lin, K.-S., Lee, C.-Y., \& Wu, H.-C. (2013). A Survey of Quality of Life and Depression for Police Officers in Kaohsiung, Taiwan. Quality of Life Research 2006 15:5, 15(5), 925-932. https://doi.org/10.1007/S11136-005-48299

Cummings, J. J., \& Bailenson, J. N. (2016). How Immersive Is Enough? A Meta-Analysis of the Effect of Immersive Technology on User Presence. Media Psychology, 19(2), 272-309. https://doi.org/10.1080/15213269.2015.1015740

Di Nota, P. M., Arpaia, J., Boychuk, E. C., Collins, P. I., \& Andersen, J. P. (2021). Testing the Efficacy of a 1-Day Police Decision-Making and Autonomic Modulation Intervention: A Pragmatic Randomized Control Trial. Frontiers in Psychology, this issue, 3490. https://doi.org/10.3389/FPSYG.2021.719046 
750

751

752

753

754

755

756

757

758

759

760

761

762

763

764

765

766

767

768

769

770

771

772

773

774

775

776

777

778

779

780

781

782

783

784

785

786

787

Di Nota, P. M., \& Huhta, J.-M. (2019). Complex Motor Learning and Police Training: Applied, Cognitive, and Clinical Perspectives. Frontiers in Psychology, O(JULY), 1797. https://doi.org/10.3389/FPSYG.2019.01797

Dirkin, G. R. (University of I. (1983). USE OF VISUAL INFORMATION UNDER STRESS. Perceptual and Motor Skills, 56, 191-198.

Driskell, J. E., Johnston, J. H., \& Salas, E. (2001). Does stress training generalize to novel settings? Human Factors, 43(1), 99-110. https://doi.org/10.1518/001872001775992471

Ebbinghaus, B. (2005). When less is more selection problems in large- $\mathrm{N}$ and small-N cross-national comparisons. International Sociology, 20(2), 133-152.

https://doi.org/10.1177/0268580905052366

Flake, J. K., Pek, J., \& Hehman, E. (2017). Construct Validation in Social and Personality Research: Current Practice and Recommendations. Social Psychological and Personality Science, 8(4), 370-378. https://doi.org/10.1177/1948550617693063

Gamble, K. R., Vettel, J. M., Patton, D. J., Eddy, M. D., Caroline Davis, F., Garcia, J. O., Spangler, D. P., Thayer, J. F., \& Brooks, J. R. (2018). Different profiles of decision making and physiology under varying levels of stress in trained military personnel. International Journal of Psychophysiology, 131(March), 73-80. https://doi.org/10.1016/j.ijpsycho.2018.03.017

Gladwin, T. E., Hashemi, M. M., van Ast, V., \& Roelofs, K. (2016). Ready and waiting: Freezing as active action preparation under threat. Neuroscience Letters, 619, 182-188. https://doi.org/10.1016/j.neulet.2016.03.027

Goessl, V. C., Curtiss, J. E., \& Hofmann, S. G. (2017). The effect of heart rate variability biofeedback training on stress and anxiety: A meta-analysis. Psychological Medicine, 47(15), 2578-2586. https://doi.org/10.1017/S0033291717001003

Gorini, A., Capideville, C. S., De Leo, G., Mantovani, F., \& Riva, G. (2011). The role of immersion and narrative in mediated presence: the virtual hospital experience. Cyberpsychology, Behavior and Social Networking, 14(3), 99-105. https://doi.org/10.1089/cyber.2010.0100

Habersaat, S., Abdellaoui, S. H., \& Wolf, J. M. (2021). Social desirability, stress and health in police officers: preliminary results. Policing, 44(2), 213-229. https://doi.org/10.1108/PIJPSM-082020-0133

Hansen, A. L., Johnsen, B. H., \& Thayer, J. F. (2009). Relationship between heart rate variability and cognitive function during threat of shock. Anxiety, Stress and Coping, 22(1), 77-89. https://doi.org/10.1080/10615800802272251

Hashemi, M. M., Gladwin, T. E., de Valk, N. M., Zhang, W., Kaldewaij, R., van Ast, V., Koch, S. B. J., Klumpers, F., \& Roelofs, K. (2019). Neural Dynamics of Shooting Decisions and the Switch from Freeze to Fight. Scientific Reports, 9(1), 1-10. https://doi.org/10.1038/s41598-019-409178

Hashemi, M. M., Zhang, W., Kaldewaij, R., Koch, S. B. J., Smit, A., Figner, B., Jonker, R., Klumpers, F., \& Roelofs, K. (2021). Human defensive freezing: associations with hair cortisol 
and trait anxiety. Psychoneuroendocrinology, 133, 105417. https://doi.org/10.1016/j.psyneuen.2021.105417

Hautus, M. J. (1995). Corrections for extreme proportions and their biasing effects on estimated values of d'. Behavior Research Methods, Instruments, \& Computers, 27(1), 46-51. https://doi.org/10.3758/BF03203619

Hayano, J., \& Yuda, E. (2019). Pitfalls of assessment of autonomic function by heart rate variability. In Journal of Physiological Anthropology (Vol. 38, Issue 1, pp. 1-8). BioMed Central. https://doi.org/10.1186/s40101-019-0193-2

Hirsch, J. A., \& Bishop, B. (1981). Respiratory sinus arrhythmia in humans: How breathing pattern modulates heart rate. American Journal of Physiology - Heart and Circulatory Physiology, 10(4), 620-629. https://doi.org/10.1152/ajpheart.1981.241.4.h620

Holzinger, A., Pichler, A., \& Maurer, H. (2006). Multi Media e-learning software TRIANGLE casestudy: experimental results and lessons learned. Journal of Universal Science and Technology of Learning, 1(1), 61-92.

Horner, R. H., Carr, E. G., Halle, J., Mcgee, G., Odom, S., \& Wolery, M. (2005). The use of singlesubject research to identify evidence-based practice in special education. In Exceptional Children (Vol. 71, Issue 2, pp. 165-179). SAGE PublicationsSage CA: Los Angeles, CA. https://doi.org/10.1177/001440290507100203

Jamieson, J. P., Mendes, W. B., Blackstock, E., \& Schmader, T. (2010). Turning the knots in your stomach into bows: Reappraising arousal improves performance on the GRE. Journal of Experimental Social Psychology, 46(1), 208-212. https://doi.org/10.1016/J.JESP.2009.08.015

Jamieson, J. P., Mendes, W. B., \& Nock, M. K. (2013). Improving Acute Stress Responses: The Power of Reappraisal. In Current Directions in Psychological Science (Vol. 22, Issue 1, pp. 5156). SAGE PublicationsSage CA: Los Angeles, CA. https://doi.org/10.1177/0963721412461500

Jiménez Morgan, S., \& Molina Mora, J. A. (2017). Effect of Heart Rate Variability Biofeedback on Sport Performance, a Systematic Review. In Applied Psychophysiology Biofeedback (Vol. 42, Issue 3, pp. 235-245). Springer US. https://doi.org/10.1007/s10484-017-9364-2

Johnson, D. J., Cesario, J., \& Pleskac, T. J. (2018). How prior information and police experience impact decisions to shoot. Journal of Personality and Social Psychology, 115(4), 601-623. https://doi.org/10.1037/PSPA0000130

Kendall, M. G. (1938). A New Measure of Rank Correlation. Biometrika, 30(1/2), 81. https://doi.org/10.2307/2332226

Klinger, D. A., \& Brunson, R. K. (2009). Police officers' perceptual distortions during lethal force situations: Informing the reasonableness standard*. Criminology \& Public Policy, 8(1), 117140. https://doi.org/10.1111/J.1745-9133.2009.00537.X

Kratochwill, T. R., Hitchcock, J. H., Horner, R. H., Levin, J. R., Odom, S. L., Rindskopf, D. M., \& Shadish, W. R. (2013). Single-Case Intervention Research Design Standards. Remedial and Special Education, 34(1), 26-38. https://doi.org/10.1177/0741932512452794 
826

827

828

829

830

831

832

833

834

835

836

837

838

839

840

841

842

843

844

845

846

847

848

849

850

851

852

853

854

855

856

857

858

859

860

861

862

863

864

Kromenacker, B. W., Sanova, A. A., Marcus, F. I., Allen, J. J. B., \& Lane, R. D. (2018). Vagal Mediation of Low-Frequency Heart Rate Variability during Slow Yogic Breathing. Psychosomatic Medicine, 80(6), 581-587. https://doi.org/10.1097/PSY.0000000000000603

Laborde, S., Allen, M. S., Borges, U., Hosang, T. J., Furley, P., Mosley, E., \& Dosseville, F. (2021). The Influence of Slow-Paced Breathing on Executive Function. Journal of Psychophysiology. https://doi.org/10.1027/0269-8803/a000279

Lane, J. D., \& Gast, D. L. (2014). Visual analysis in single case experimental design studies: Brief review and guidelines. In Neuropsychological Rehabilitation (Vol. 24, Issues 3-4, pp. 445463). Neuropsychol Rehabil. https://doi.org/10.1080/09602011.2013.815636

Leppma, M., Mnatsakanova, A., Sarkisian, K., Scott, O., Adjeroh, L., Andrew, M. E., Violanti, J. M., \& Mccanlies, E. C. (2017). Stressful life events and posttraumatic growth among police officers: A cross-sectional study. Stress and Health, October 2016, 1-12. https://doi.org/10.1002/smi.2772

Lin, J. H. T. (2017). Fear in virtual reality (VR): Fear elements, coping reactions, immediate and next-day fright responses toward a survival horror zombie virtual reality game. Computers in Human Behavior, 72, 350-361. https://doi.org/10.1016/j.chb.2017.02.057

Lobel, A., Gotsis, M., Reynolds, E., Annetta, M., Engels, R. C. M. E., \& Granic, I. (2016). Designing and utilizing biofeedback games for emotion regulation: The case of Nevermind. Conference on Human Factors in Computing Systems - Proceedings, 07-12-May-2016, 1945-1951. https://doi.org/10.1145/2851581.2892521

Maier, S. U., Makwana, A. B., \& Hare, T. A. (2015). Acute Stress Impairs Self-Control in GoalDirected Choice by Altering Multiple Functional Connections within the Brain's Decision Circuits. Neuron, 87(3), 621-631. https://doi.org/10.1016/J.NEURON.2015.07.005

Manolov, R., Moeyaert, M., \& Evans, J. J. (2015). Resources and guidelines for analysing SCED data \&quot; Further developments in summarising and meta-analysing single-case data: An illustration with neurobehavioural interventions in acquired brain injury\&quot; (Manuscript submitted for publication) Exten. Neuropsychological Rehabilitation, 24(3-4), 1-238. https://doi.org/https://doi.org/10.1080/09602011.2014.903199

Mather, M., \& Thayer, J. F. (2018). How heart rate variability affects emotion regulation brain networks. Current Opinion in Behavioral Sciences, 19, 98-104. https://doi.org/10.1016/j.cobeha.2017.12.017

McAuley, E. D., Duncan, T., \& Tammen, V. V. (1989). Psychometric properties of the intrinsic motivation inventoiy in a competitive sport setting: A confirmatory factor analysis. Research Quarterly for Exercise and Sport, 60(1), 48-58. https://doi.org/10.1080/02701367.1989.10607413

McCall, C., Hildebrandt, L. K., Bornemann, B., \& Singer, T. (2015). Physiophenomenology in retrospect: Memory reliably reflects physiological arousal during a prior threatening experience. Consciousness and Cognition, 38, 60-70. https://doi.org/10.1016/j.concog.2015.09.011

Mccanlies, E. C., Mnatsakanova, A., Andrew, M. E., Burchfiel, C. M., \& Violanti, J. M. (2014). 
Positive psychological factors are associated with lower PTSD symptoms among police officers: Post Hurricane Katrina. Stress and Health, 30(5), 405-415. https://doi.org/10.1002/smi.2615

Mccraty, R., \& Atkinson, M. (2012). Resilience Training Program Reduces Physiological and Psychological Stress in Police Officers. Global Advances in Health and Medicine, 1(5), 44-66. https://doi.org/10.7453/gahmj.2012.1.5.013

McCraty, R., Atkinson, M., Lipsenthal, L., \& Arguelles, L. (2009). New Hope for Correctional Officers: An Innovative Program for Reducing Stress and Health Risks. Applied Psychophysiology and Biofeedback 2009 34:4, 34(4), 251-272. https://doi.org/10.1007/S10484009-9087-0

McFall, R. M., \& Treat, T. A. (1999). Quantifying the information value of clinical assessments with signal detection theory. Annual Review of Psychology, 50, 215-241. https://doi.org/10.1146/annurev.psych.50.1.215

Mendes, W. B., Gray, H. M., Mendoza-Denton, R., Major, B., \& Epel, E. S. (2007). Why egalitarianism might be good for your health: Physiological thriving during stressful intergroup encounters. Psychological Science, 18(11), 991-998. https://doi.org/10.1111/j.14679280.2007.02014.x

Michela, A., van Rooij, M. M. J. W. M. M. J. W., Klumpers, F., van Peer, J. M. J. M., Roelofs, K., \& Granic, I. (2019). Reducing the Noise of Reality. Psychological Inquiry, 30(4), 203-210. https://doi.org/10.1080/1047840X.2019.1693872

Miller, L. C., Shaikh, S. J., Jeong, D. C., Wang, L., Gillig, T. K., Godoy, C. G., Appleby, P. R., Corsbie-Massay, C. L., Marsella, S., Christensen, J. L., \& Read, S. J. (2019). Causal Inference in Generalizable Environments: Systematic Representative Design. Psychological Inquiry, 30(4), 173-202. https://doi.org/10.1080/1047840X.2019.1693866

Nieuwenhuys, A., \& Oudejans, R. R. D. (2011). Training with anxiety: Short-and long-term effects on police officers' shooting behavior under pressure. Cognitive Processing, 12(3), 277-288. https://doi.org/10.1007/s10339-011-0396-x

Nieuwenhuys, A., Savelsbergh, G. J. P., \& Oudejans, R. R. D. (2015). Persistence of threat-induced errors in police officers' shooting decisions. Applied Ergonomics, 48, 263-272. https://doi.org/10.1016/j.apergo.2014.12.006

Oostenveld, R. (n.d.). GitHub - eegsynth/eegsynth: Converting real-time EEG into sounds, music and visual effects. Retrieved October 10, 2021, from https://github.com/eegsynth/eegsynth

Parsons, T. D. (2015). Virtual Reality for Enhanced Ecological Validity and Experimental Control in the Clinical, Affective and Social Neurosciences. Frontiers in Human Neuroscience, 9. https://doi.org/10.3389/fnhum.2015.00660

Porcelli, A. J., \& Delgado, M. R. (2017). Stress and decision making: effects on valuation, learning, and risk-taking. Current Opinion in Behavioral Sciences, 14, 33-39. https://doi.org/10.1016/j.cobeha.2016.11.015

Riva, G., Mantovani, F., Capideville, C. S., Preziosa, A., Morganti, F., Villani, D., Gaggioli, A., 
903

904

905

906

907

908

909

910

911

912

913

914

915

916

917

918

919

920

921

922

923

924

925

926

927

928

929

930

931

932

933

934

935

936

937

938

939

940

Botella, C., \& Alcañiz, M. (2007). Affective interactions using virtual reality: The link between presence and emotions. Cyberpsychology and Behavior, 10(1), 45-56.

https://doi.org/10.1089/cpb.2006.9993

Rockstroh, C., Blum, J., \& Göritz, A. S. (2019). Virtual reality in the application of heart rate variability biofeedback. International Journal of Human Computer Studies, 130, 209-220. https://doi.org/10.1016/j.ijhcs.2019.06.011

Russo, M. A., Santarelli, D. M., \& O'Rourke, D. (2017). The physiological effects of slow breathing in the healthy human. In Breathe (Vol. 13, Issue 4, pp. 298-309). European Respiratory Society. https://doi.org/10.1183/20734735.009817

Scholten, H., \& Granic, I. (2019). Use of the principles of design thinking to address limitations of digital mental health interventions for youth: Viewpoint. Journal of Medical Internet Research, 2l(1), 1-14. https://doi.org/10.2196/11528

Schoneveld, E. A., Lichtwarck-Aschoff, A., \& Granic, I. (2019). What keeps them motivated? Children's views on an applied game for anxiety. Entertainment Computing, 29, 69-74. https://doi.org/10.1016/j.entcom.2018.12.003

Schoneveld, E. A., Malmberg, M., Lichtwarck-Aschoff, A., Verheijen, G. P., Engels, R. C. M. E., \& Granic, I. (2016). A neurofeedback video game (MindLight) to prevent anxiety in children: A randomized controlled trial. Computers in Human Behavior, 63, 321-333. https://doi.org/10.1016/j.chb.2016.05.005

Schwerdtfeger, A. R., Schwarz, G., Pfurtscheller, K., Thayer, J. F., Jarczok, M. N., \& Pfurtscheller, G. (2020). Heart rate variability (HRV): From brain death to resonance breathing at 6 breaths per minute. Clinical Neurophysiology, 131(3), 676-693. https://doi.org/10.1016/j.clinph.2019.11.013

Seifert, L., Papet, V., Strafford, B. W., Coughlan, E. K., \& Davids, K. (2018). Skil transfer, expertise and talent development: An ecological dynamics perspective. Movement and Sports Sciences Science et Motricite, 2018(102), 39-49. https://doi.org/10.1051/sm/2019010

Shaffer, F., \& Ginsberg, J. P. (2017). An Overview of Heart Rate Variability Metrics and Norms. Frontiers in Public Health, 0, 258. https://doi.org/10.3389/FPUBH.2017.00258

Shaffer, F., McCraty, R., \& Zerr, C. L. (2014). A healthy heart is not a metronome: an integrative review of the heart's anatomy and heart rate variability. Frontiers in Psychology, 5, 1040. https://doi.org/10.3389/fpsyg.2014.01040

Skolnick, J. H., \& McCoy, C. (1984). Police Accountability and the Media. Law \& Social Inquiry, 9(3), 521-557. https://doi.org/10.1111/j.1747-4469.1984.tb00019.x

Slater, M. (2018). Immersion and the illusion of presence in virtual reality. In British Journal of Psychology (Vol. 109, Issue 3, pp. 431-433). John Wiley and Sons Ltd. https://doi.org/10.1111/bjop.12305

Smith, J. D. (2012). Single-case experimental designs: A systematic review of published research and current standards. Psychological Methods, 17(4), 510-550. https://doi.org/10.1037/a0029312 
941

942

943

944

945

946

947

948

949

950

951

952

953

954

955

956

957

958

959

960

961

962

963

964

965

966

967

968

969

970

971

972

973

974

975

976

977

Smith, P. L., \& Little, D. R. (2018). In defense of the small-N design. Psychonomic Bulletin and Review, 25, 2083-2101. https://doi.org/10.3758/s13423-018-1451-8

Srinivasan, K., Sucharita, S., \& Vaz, M. (2002). Effect of standing on short term heart rate variability across age. Clinical Physiology and Functional Imaging, 22(6), 404-408. https://doi.org/10.1046/j.1475-097X.2002.00450.x

Staller, M. S., \& Körner, S. (2019). Commentary: Complex Motor Learning and Police Training: Applied, Cognitive, and Clinical Perspectives. Frontiers in Psychology, 10, 2444. https://doi.org/10.3389/fpsyg.2019.02444

Stanislaw, H., \& Todorov, N. (1999). Calculation of signal detection theory measures. Behavior Research Methods, Instruments, \& Computers, 3(I), 37-149.

Stetz, M. C., Thomas, M. L., Russo, M. B., Stetz, T. A., Wildzunas, R. M., McDonald, J. J., Wiederhold, B. K., \& Romano, J. A. (2007). Stress, Mental Health, and Cognition: A Brief Review of Relationships and Countermeasures. Aviation, Space, and Environmental Medicine, 78(5,suppl), B252-B260.

Tarlow, K. R. (2017a). An Improved Rank Correlation Effect Size Statistic for Single-Case Designs: Baseline Corrected Tau. In Behavior Modification (Vol. 41, Issue 4). https://doi.org/10.1177/0145445516676750

Tarlow, K. R. (2017b). Baseline Corrected Tau for single-case research ( $R$ code). Retrieved from http://ktarlow.com/stats/.http://ktarlow.com/stats/r/bctau.txt

Tarlow, K. R. (2018). R functions for meta-analysis (R code). Retrieved from http://ktarlow.com/stats/.http://ktarlow.com/stats/r/meta.txt

Taylor, P. L. (2019). Dispatch Priming and the Police Decision to Use Deadly Force. Police Quarterly, 109861111989665. https://doi.org/10.1177/1098611119896653

van der Meulen, E., Bosmans, M. W. G., Lens, K. M. E., Lahlah, E., \& van der Velden, P. G. (2018). Effects of Mental Strength Training for Police Officers: a Three-Wave Quasi-experimental Study. Journal of Police and Criminal Psychology, 33(4), 385-397. https://doi.org/10.1007/s11896-017-9247-8

van der Ploeg, H. M. (1984). The development and validation of the Dutch form of the Test Anxiety Inventory. Applied Psychology, 33(2), 243-254. https://doi.org/10.1111/J.14640597.1984.TB01432.X

Vogel, S., Klumpers, F., Kroes, M. C. W., Oplaat, K. T., Krugers, H. J., Oitzl, M. S., Joëls, M., \& Fernández, G. (2015). A Stress-Induced Shift from Trace to Delay Conditioning Depends on the Mineralocorticoid Receptor. Biological Psychiatry, 78(12), 830-839. https://doi.org/10.1016/j.biopsych.2015.02.014

Weerdmeester, J., Van Rooij, M. M. J. M., Engels, R. C. M. E., \& Granic, I. (2020). An integrative model for the effectiveness of biofeedback interventions for anxiety regulation: Viewpoint. Journal of Medical Internet Research, 22(7). https://doi.org/10.2196/14958

This is a provisional file, not the final typeset article 
978

979

980

981

982

983

984

985

986

987

988

989

990

991

992

993

994

995

996

997

998

999

1000

1001

1002

1003

1004

1005

1006

1007

1008

1009

1010

1011

1012

1013

West, C., Fekedulegn, D., Andrew, M., Burchfiel, C. M., Harlow, S., Bingham, C. R., McCullagh, M., Park, S. K., \& Violanti, J. (2017). On-Duty Nonfatal Injury that Lead to Work Absences Among Police Officers and Level of Perceived Stress. Journal of Occupational and

Environmental Medicine, XX(X), 1. https://doi.org/10.1097/JOM.0000000000001137

Wilson, C. J., \& Soranzo, A. (2015). The Use of Virtual Reality in Psychology: A Case Study in Visual Perception. Computational and Mathematical Methods in Medicine, 2015. https://doi.org/10.1155/2015/151702

WMA. (2018). WMA Declaration of Helsinki - Ethical Principles for Medical Research Involving Human Subjects - WMA - The World Medical Association. In WMA Declaration of Helsinki Ethical principles for medical research involving human subjects. https://www.wma.net/policies-post/wma-declaration-of-helsinki-ethical-principles-for-medicalresearch-involving-human-subjects/

Young, M. E., Sutherland, S. C., \& McCoy, A. W. (2017). Optimal go/no-go ratios to maximize false alarms. Behavior Research Methods 2017 50:3, 50(3), 1020-1029. https://doi.org/10.3758/S13428-017-0923-5

\section{Conflict of Interest}

The authors declare that the research was conducted in the absence of any commercial or financial relationships that could be construed as a potential conflict of interest.

\section{Author Contributions}

AM wrote the article, conceptualized the VR environment and experiment, collected and analysed the data. JvP conceptualized the VR environment. JCB conceptualized and implemented the biofeedback, and analyzed the data. AN contributed to write the methods, conceptualized the experiment and collected the data. MMJMvR conceptualized the experiment and analysed the data. RO supervised the implementation of the biofeedback. WD conceptualized the VR environment, provided the theoretical policing framework and coordinated data collection. AS coordinated data collection. KR conceptualized the VR environment, FK conceptualized the VR environment and experiment, and analysed the data. IG conceptualized the VR environment and experiment.

All authors reviewed and contributed to the manuscript

\section{$9 \quad$ Funding}

This work was supported by the NWO Creative Industry grant \# 055.16.1392795 awarded to KR, IG, and FK.

\section{Acknowledgments}

We would like to thank the police trainers from the Sevenum IBT centre for their time and dedication. We also would like to thank Ken Koontz (https://www.kenkoontz. com/), Erik van den Berge and Thijs Doornbos for their design and implementation work for the VR environment.

\section{Data Availability Statement}


Running Title

1014 Due to privacy concerns, as the dataset contains performance indexes of police officers, the datasets

1015 analyzed for this study can only be obtained by requesting it to the corresponding author at 1016 abele.michela@gmail.com 